Published in final edited form as:

Int Urogynecol J. 2013 February ; 24(2): 295-302. doi:10.1007/s00192-012-1829-5.

\title{
CAFFEINE AND URINARY INCONTINENCE IN US WOMEN
}

\author{
Jonathan L. Gleason, M.D. ${ }^{1}$, Holly E. Richter, Ph.D., M.D. ${ }^{1}$, David T. Redden, Ph.D. ${ }^{2,4}$, \\ Patricia S. Goode, M.D. ${ }^{2,3}$, Kathryn L. Burgio, PhD. ${ }^{2,3}$, and Alayne D. Markland, D.O., M.Sc. \\ 2,3 \\ ${ }^{1}$ Department of Obstetrics and Gynecology, Division of Urogynecology and Pelvic Reconstructive \\ Surgery, University of Alabama at Birmingham, Birmingham, Alabama \\ ${ }^{2}$ Department of Veterans Affairs Medical Center, Birmingham, Alabama \\ ${ }^{3}$ Department of Medicine, Division of Gerontology, Geriatrics, and Palliative Care, University of \\ Alabama at Birmingham, Birmingham, Alabama \\ ${ }^{4}$ School of Public Health, University of Alabama at Birmingham, Birmingham, Alabama
}

\begin{abstract}
Introduction and Hypothesis-The goal of this study was to characterize associations between caffeine consumption and severity of urinary incontinence (UI) in US women. We hypothesized that moderate and high caffeine intake would be associated with UI in US women when controlling for other factors associated with UI.

Methods-US women participated in the 2005-2006 and 2007-2008 National Health and Nutrition Examination Survey (NHANES), a cross-sectional, nationally representative survey. Using the Incontinence Severity Index, UI was categorized as "any" and "moderate/severe". Types of UI included stress, urge, mixed, and other. Food diaries were completed and average water ( $\mathrm{gm} /$ day), total dietary moisture ( $\mathrm{gm} /$ day), and caffeine ( $\mathrm{mg} /$ day) intake were calculated into quartiles. Step-wise logistic regression models were constructed adjusting for: sociodemographics, chronic diseases, body mass index, self-rated health, depression, alcohol use, dietary water and moisture in take, and reproductive factors.
\end{abstract}

Results-From the 4309 non-pregnant women (aged $\geq 20$ years) who had complete UI and dietary data, UI prevalence for any UI was $41.0 \%$ and $16.5 \%$ for moderate/severe UI, with stress UI the most common UI type (36.6\%). Women consumed a mean caffeine intake of $126.7 \mathrm{mg} /$ day. After adjusting for multiple factors, caffeine in take in the highest quartile ( $2204 \mathrm{mg} / \mathrm{day}$ ) was associated with any UI (prevalence odds ratio (POR)1.47, 95\% CI 1.07, 2.01), but not moderate/ severe UI (POR 1.42, 95\% CI 0.98, 2.07). Type of UI (stress, urgency, mixed) was not associated with caffeine intake.

Conclusions-Caffeine intake $\geq 204 \mathrm{mg} /$ day was associated with any UI, but not moderate/ severe UI, in US women.

Corresponding Author: Jonathan L. Gleason, M.D. $17006^{\text {th }}$ Avenue South, Suite 10382. Birmingham, Alabama. 35233 (P) 205/934-1704, (F) 205/975-8893, gleasj@ gmail.com.

Disclaimer/Conflict of Interest: JL Gleason -none; HE Richter -none; DT Redden -none; PS Goode -none; KL Burgio -none; AD Markland -none.

Authors Contributions: JL Gleason -protocol/project development, data management, data analysis, manuscript writing/editing; HE Richter -protocol/project development, manuscript writing/editing; DT Redden -Data analysis,-manuscript editing; PS Goode manuscript writing/editing; KL Burgio - manuscript writing/editing; AD Markland -protocol/project development, data management, data analysis, manuscript writing/editing. 


\section{Keywords}

urinary; incontinence; caffeine; intake; women

\section{Introduction}

Urinary Incontinence (UI) is a prevalent condition with significant negative impact on quality of life and overall health. UI prevalence estimates vary considerably according to the definition used and among community-dwelling women ranges from 10-40\% [1-4].

Caffeine is consumed more than any other stimulant drug in the world. The amount of caffeine in fluid varies considerably with coffee containing from 95 to $206 \mathrm{mg} / 8 \mathrm{oz}$ cup, tea from 14 to $120 \mathrm{mg} / 8 \mathrm{oz}$ cup, and carbonated beverages contain as high as $55 \mathrm{mg} / 12 \mathrm{oz}$ serving [5]. Most Americans consume caffeine and it has been reported that approximately $80 \%$ of women drink caffeine-containing beverages daily [6]. The consumption of highenergy drinks with large amounts of caffeine $(50-505 \mathrm{mg} / \mathrm{serving})$ is also on the rise in the United States(US) population[7].

Caffeine has a diuretic effect and also may affect the bladder by increasing detrusor pressure and promoting detrusor muscle excitability [8-11]. Epidemiologic and clinical cohort studies have demonstrated mixed results regarding the relationship of caffeine and fluid intake on UI in women [12-16]. Two large epidemiologic studies found conflicting conclusions on whether caffeine impacts incontinence [17,18]. Little robust evidence exists on caffeine and fluid management strategies. One randomized trial found a reduction in urinary urgency and frequency with caffeine reduction, while others have found that reducing excess fluid intake is beneficial[19,20].

Given the existing data, we hypothesized that moderate and high caffeine intake were associated with UI in US women when controlling for other factors associated with UI. We sought to further investigate the association between caffeine intake and urinary incontinence in an age-and racially-representative sample of community dwelling women from the US.

\section{Materials and Methods}

We utilized the publically available data from the 2005-06 and 2007-08 National Health and Nutritional Examination Surveys (NHANES) for this analysis. NHANES data are crosssectional surveys of the nationally representative, non-institutionalized US population that are sampled bi-annually using a complex, stratified, multi-stage, probability cluster design. The National Center for Health Statistics Ethics Review Board and the University of Alabama at Birmingham Institutional Review Board approved the protocol.

NHANES participants were interviewed in their homes and then underwent standardized physical examination, including measured height and weight, and further questioning in a mobile examination center (MEC). Questions regarding UI were assessed by computerassisted personal interviews methodology (CAPI). To define UI, we analyzed the data from the validated 2-item Incontinence Severity Index (ISI), which measures incontinence volume and incontinence frequency. The responses on the two questions are used to obtain a severity score ranging from 1 to 12 , with an ISI score $\geq 3$ categorized as moderate/severe UI [21]. Moderate/severe UI corresponds to at least weekly leakage or monthly leakage of volumes more than just drops. The question: "During the past 12 months, have you leaked or lost control of even a small amount of urine with activity like coughing, lifting, or exercise?" defined stress UI. Urge UI was defined based on the question: " During the past 12 months, 
have you leaked or lost control of even a small amount of urine with an urge or pressure to urinate and you couldn't get to the toilet fast enough?" In women who responded negatively to the stress and urge UI questions, a positive response to the question, "During the past 12 months, have you leaked or lost control of even a small amount of urine during nonphysical activities?" defined "other" incontinence. Positive responses to both the stress and urge UI questions defined mixed UI.

A multiple-pass dietary recall method, developed and validated by the US Department of Agriculture, was used for the dietary data [22]. Participants took part in two 24-hour dietary recall periods. The first 24-hour dietary recall was done during the initial CAPI and the second 24-hour dietary recall was done 3 to 10 days later by telephone.

From the two 24-hour dietary recall data, we reported averaged caffeine consumption (mg/ day), water intake (gm/day), consisting of tap, bottled, plain or carbonated, sweet or unsweetened water, and total moisture (gm/day), consisting of all moisture present in foods and beverages[22]. Caffeine intake was categorized into quartiles based on the distribution of intake with lower (0-27 mg/day), lower middle (28-95 mg/day), upper middle (96-204 $\mathrm{mg} /$ day), and upper (>204 $\mathrm{mg} /$ day) quartiles. We analyzed both the upper quartile and the upper tenth percentile ( $2348 \mathrm{mg} /$ day) for association with UI. Caffeine intake was calculated from fluid (coffee, tea, and soda) and from food sources (chocolate)[22].

Water intake (tap, bottled, plain or carbonated, sweet or unsweetened water in grams) was divided into quartiles, with high water intake defined by the upper quartile. Total dietary moisture (from both foods and beverages) was categorized into quartiles and the upper quartile for moisture defined high intake. Alcohol intake was obtained through the alcohol use questionnaire and was dichotomized as "never drank alcohol" and "prior or current alcohol consumption”.

Women self-reported their race/ethnicity and age was categorized in 10-year increments. BMI $\left(\mathrm{kg} / \mathrm{m}^{2}\right)$ was categorized as less than 25.0 (underweight/normal weight), 25.0 to 29.9 (overweight), and 30.0 or more (obese). Education was categorized as up to a high school education (including a General Education Development or equivalent) or more than high school. The poverty income ratio (an indicator of socioeconomic status that uses the ratio of income to the family's poverty threshold set by the US Census Bureau) was categorized as less than 1 (below the poverty threshold), 1 to 2 (1-2x the poverty threshold), and greater than 2 ( $2 x$ the poverty threshold).

Chronic disease data were ascertained through the questions "Has a doctor or other health professional told you that you had [diseases]?" Chronic diseases included: arthritis, stroke, emphysema, chronic bronchitis, asthma, coronary heart disease, angina, myocardial infarction, hypertension, and diabetes mellitus. Diabetes also included taking insulin and/or diabetic pills. The definition of hypertension included the diagnosis and/or taking antihypertensive medications. The cumulative number of chronic diseases was categorized as: $0,1,2$, and 3 or more chronic diseases.

Self-rated general health status was defined by the question, "Would you say that in general your health is excellent, very good, good, fair, or poor?" Responses to this question were aggregated into 2 categories: excellent, very good or good health versus fair or poor. Depression was assessed using the validated Patient Health Questionnaire-9 (PHQ-9). The PHQ-9 yields scores from 0 to 27, and scores $\geq 10$ used to define major depression[23].

From the NHANES reproductive health questions, vaginal deliveries, hormone therapy use, and prior hysterectomy were included. Vaginal births were categorized as none, 1-2, 3-4, or $\geq 4$ and had a missing data rate of $25 \%$. Hormone therapy use was ascertained with the 
question, "Have you ever used female hormones such as estrogen and progesterone? Data on having a prior hysterectomy had a missing rate of $28 \%$; therefore, women who reported having a period in the prior 12-months were also categorized as not having had a hysterectomy. Vaginal bulging was defined by the question: "Do you experience bulging or something falling out that you can see or feel in the vaginal area?" from the Pelvic Floor Distress Inventory [24].

All statistical analyses were calculated using STATA 8.2 (STATA Corp. College Station, Texas), which incorporates the design effect, appropriate sample weights, and the stratification and clustering of the complex NHANES sample design [25]. The Pearson's $\chi^{2}$ test assessed the association between UI outcomes and demographic and medical characteristics with prevalence estimates and 95\% confidence intervals (CI). Estimates with relative standard errors greater than $30 \%$ were identified as statistically unreliable. Multivariable logistic regression models were constructed using variables in a stepwise fashion with sociodemographic variables in Step 2 (age, race/ethnicity, education, and poverty status), comorbidity and BMI (Step 3), self-rated health and depression (Step 4), alcohol intake (Step 5), total fluid and moisture intake (Step 6), hysterectomy and the use of hormone replacement therapy (Step 7), and vaginal deliveries (Step 8). Given the decrease in the sample size by $25 \%(\mathrm{n}=1552)$ by including women who had missing data on vaginal deliveries, this variable was included individually in the multivariable models. Prevalence odds ratios (POR) and 95\% CIs were reported with the level of statistical significance set at $\mathrm{p}<0.05$.

\section{Results}

A total of 10,914 NHANES participants aged 20 years and older were interviewed in their homes and then underwent standardized physical examination, including measured height and weight, and further questioning in a mobile examination center (MEC). After excluding men $(n=5297)$, women who were pregnant at the time of the interview $(n=393)$, women with incomplete UI data $(n=745)$, and those with incomplete caffeine intake data $(n=170)$ were excluded. A total of 4309 women were included in the final analytic data set. Women with missing data on UI or dietary recall for caffeine and water intake $(n=915 / 5617,16.2 \%)$ were more likely to be $\geq 80$ years of age, African American, and have less than a high school education $(\mathrm{p}<0.05)$.

UI prevalence was $41.0 \%(95 \%$ CI 38.9, 43.2) for any UI and 16.5\% (95\% CI 15.0, 18.1) for moderate/severe UI. In addition, 36.6\% (95\% CI 33.8, 39.5) reported stress UI, 17.0\% (95\% CI 15.2, 18.9) reported urge UI, $25.5 \%$ (95\% CI 23.6, 27.4) reported mixed UI, and 7.8\% (95\% CI 6.7, 9.1) had "other" UI.

In univariate analyses, UI was significantly associated $(\mathrm{p}<0.005)$ with several factors including: age, race/ethnicity, less education, low poverty-income ratio, obesity, "fair/poor" self-rated health, major depression, having more chronic diseases, alcohol use, the use of hormone replacement therapy, history of a hysterectomy, increasing number of vaginal deliveries ( 0 vs $1,2,3$, and 4 or more) and reporting a vaginal bulge (Table 1). The prevalence of UI increased in the population by quartile of caffeine intake ( $\mathrm{p}$ for trend $<0.001$, Figure 1)with the prevalence of any UI ranging from $34 \%$ in lower quartile to $49 \%$ in the upper quartile.

Mean caffeine intake was $127 \mathrm{mg}$ day (range 0 to $2715 \mathrm{mg} /$ day).In the univariate analyses (Table 2), caffeine intake in the upper quartile ( $\geq 204 \mathrm{mg} /$ day) was associated with any UI ( $\mathrm{p}<$ $0.001)$ and moderate/severe UI ( $\mathrm{p}=0.005)$. Caffeine intake in the top tenth percentile of intake ( $3348 \mathrm{mg} /$ day), was significantly associated with a higher prevalence of any UI 
( $\mathrm{p}=0.008)$, but not moderate/severe UI ( $\mathrm{p}=0.23)$. Water intake in the upper quartile $(>1304 \mathrm{~mL}$ per day) was associated with a lower prevalence of moderate/severe UI ( $\mathrm{p}<$ 0.001 ), but no association was seen with any UI. Total moisture in the upper quartile ( 23319 $\mathrm{gm} /$ day) was associated with any UI $(\mathrm{p}=0.001)$, but was not associated with moderate/severe UI (Table 2).

In the multivariable models (Table 3 ), caffeine intake in the highest quartile(>204 $\mathrm{mg} /$ day) was associated with any UI (POR 1.47, 95\% CI 1.07, 2.07) after controlling for significant factors (age, race/ethnicity, poverty income ratio, BMI, self-rated health status, major depression, chronic diseases, alcohol use, water intake, total dietary moisture intake, and reproductive factors in women including vaginal deliveries). However, the odds ratio for caffeine intake in the top quartile and moderate/severe UI was not significant when vaginal deliveries were included in the model (POR 1.42, 95\% CI 0.98, 2.07). When examining the top $10^{\text {th }}$ percentile for caffeine intake, no associations were seen for any UI (POR $1.23,95 \%$ CI $0.70,2.12$ ) or moderate/severe UI (POR $0.90,95 \%$ CI $0.43,1.87$ ) when vaginal deliveries were included in the model. Caffeine intake was not associated $(p>0.05)$ in a separate multivariable analysis according to UI type(stress, urge, mixed, or other).

\section{Discussion}

Results from the 2005-2006 and 2007-2008 NHANES indicated that among a representative sample of US women aged 20 years and above, the prevalence of any UI was associated with caffeine intake $\geq 204 \mathrm{mg} /$ day (POR 1.42, 95\% CI 1.07, 2.07), even after controlling for other UI risk factors including water and total moisture intake. When evaluating the severity of UI symptoms, no relationship with moderate/severe UI and caffeine intake was found. Types of UI (stress, urge, and mixed UI) were not associated with moderate or high caffeine intake when controlling for other UI risk factors.

Previous cross-sectional studies have reported conflicting findings regarding the relationship of caffeine intake and UI[12-15]. Two large epidemiologic studies reported opposing conclusions about the relationship of caffeine and UI. Dalosso et al found no association between tea or coffee consumption and stress UI or overactive bladder symptoms in the 39,603 male and female participants in the Leicestershire MRC Incontinence Study in the UK [17]. More recently, Jura et al recently reported data from the Nurses' Health Study characterizing measured caffeine intake and the presence of UI[18]. Their conclusion that high caffeine intake( $>450 \mathrm{mg}$ /day)was associated (RR 1.3, 95\% CI 1.0, 1.8) with frequent UI ( $₫$ weekly) and urgency UI (RR $1.42,95 \%$ CI 1.04, 1.95) is similar to our findings that caffeine intake $2204 \mathrm{mg}$ /day was associated any UI (OR 1.47, 95\% CI 1.07, 2.01). We observed a similar trend in the association of caffeine intake with moderate/severe UI, but it did not reach statistical significance in the final multivariable model (POR 1.42, 95\% CI $0.98,2.07)$. This is likely due to the $42 \%$ reduction in the sample size when vaginal delivery is added to the model and results in an increase in the POR, but a widening of the $95 \%$ CI to include one (Table 3). Without vaginal deliveries in the model, caffeine intake was associated with moderate/severe UI (POR 1.40, 95\% CI 1.10, 1.75).

The study by Jura et al was limited by the lack of ethnic diversity (95\% White), and the failure to control for multiple factors known to affect continence (alcohol use, prior hysterectomy, presence of pelvic organ prolapse, number of chronic diseases, and depression). Furthermore, their assessment of fluid intake only included fluid obtained from beverages without data provided about total fluid intake including moisture in foods. Others have previously demonstrated that up to $18 \%$ of total moisture intake comes from sources other than beverages [26]. Recent data from the Swedish Twins Registry showed no 
association of coffee and tea consumption and UI in twins, but did not account for other sources of caffeine or total fluid intake [16].

In the multivariable model for moderate/severe UI, we found that women with high water intake were less likely to have UI(data not shown in Table 2, POR 0.71, 95\% CI 0.55, 0.91). Furthermore, no association was seen with UI and total moisture intake. Due to the crosssectional design of this study, we are unable to imply causation. An explanation for this finding may be that women with UI symptoms may reduce fluid intake, rather than that increased fluid intake reduces incontinence. However, one small trial evaluating behavioral therapy for the treatment of UI that included increasing fluid intake in women with low fluid intake showed a reduction in UI episodes and amount of urine loss [27].

Based on our findings, moderation of caffeine intake remains a reasonable part of the multicomponent treatment approach for UI, but more adequately powered, randomized, controlled trials are needed. Caffeine has been found to have a diuretic effect and may also have an effect on smooth muscle contractions in the bladder. In one case control study, high caffeine intake ( $>400 \mathrm{mg} /$ day) was associated with detrusor instability on cystometric evaluation [12]. Bryant et al found a 35\% reduction in voids per day and $61 \%$ reduction in occasions of urgency symptoms after one month of caffeine reduction in a randomized controlled trial [19]. Caffeine reduction may be more important for women with UI who consume higher daily levels of caffeine (1-2 cups of coffee or several glasses or cups of tea or soda daily) than women who consume lower caffeine levels. Prospective studies are needed to guide clinical practice.

Our study is strengthened by the large sample size with a representative population of US women, specifically designed to oversample women in specific racial/ethnic groups and age groups. Also, a validated measure for UI was used to determine the presence and severity of UI symptoms that enabled us to use two UI definitions (any vs. moderate/severe UI). The validated dietary recall methodology from NHANES that allows for measurement of moisture intake from foods is another strength of this study [22]. Finding an association between caffeine intake and UI after controlling for factors, such as age, race, BMI, moisture intake, alcohol use, hysterectomy and vaginal deliveries, that are recognized risk factors for incontinence, strengthens our conclusions as well. A limitation of NHANES data is that it is cross-sectional in design; therefore, although an association between UI and moderate caffeine intake was noted, we are unable to imply causation. Furthermore, our analysis was dependent on self-reported symptoms of UI and caffeine intake. Questions for UI type were not validated and the data was not analyzed according to UI type/severity. We also were not able to account for the type of caffeine consumed or the timing of the caffeine or fluid consumption.

\section{Conclusions}

Our findings support the association of higher caffeine intake ( $\geq 204 \mathrm{mg} /$ day, the amount in one 8-ounce cup of coffee per day) and urinary incontinence. A decrease in caffeine intake should be discussed in women with any UI.

\section{Acknowledgments}

Financial Support or Funding: Partially funded by the National Institute of Diabetes and Digestive and Kidney Diseases 2K24-DK068389 to HER. 


\section{References}

1. Nygaard I, Barber MD, Burgio KL, et al. Pelvic Floor Disorders Network. Prevalence of symptomatic pelvic floor disorders in US women. JAMA. 2008; 300:1311. [PubMed: 18799443]

2. Coyne KS, Sexton CC, Thompson CL, et al. The prevalence of lower urinary tract symptoms (LUTS) in the USA, the UK and Sweden: results from the Epidemiology of LUTS (EpiLUTS) study. BJU Int. 2009; 104:352. [PubMed: 19281467]

3. Hunskaar S, Burgio K, Diokno A, et al. Epidemiology and natural history of urinary incontinence in women. Urology. 2003; 62:16. [PubMed: 14550833]

4. Tennstedt SL, Link CL, Steers WD, et al. Prevalence and risk factors for urine leakage in a racially and ethnically diverse population of adults. The Boston Area Community Health (BACH) Survey. Am J Epidemiol. 2008; 167:390. [PubMed: 18182376]

5. Caffeine content for coffee, tea, soda and more. Mayo Clinic; p. 1211Available at http:// www.mayoclinic.com/health/caffeine/ANORetrieved January 3, 2012

6. Nawrot P, Jordan S, Eastwood J, et al. Effects of caffeine on human health. Food Addit Contam. 2003; 20:1. [PubMed: 12519715]

7. Arria AM, O’Brien MC. The "high" risk of energy drinks. JAMA. 2011; 305:600. [PubMed: 21266673]

8. Riesenhuber A, Boehm M, Posch M, et al. Diuretic potential of energy drinks. Amino Acids. 2006; 31:81. [PubMed: 16847703]

9. Creighton SM, Stanton SL. Caffeine: does it affect your bladder? Br J Urol. 1990; 66:613. [PubMed: 2265333]

10. Lee JG, Wein AJ, Levin RM. The effect of caffeine on the contractile response of the rabbit urinary bladder to field stimulation. Gen Pharmacol. 1993; 24:1007. [PubMed: 8224728]

11. Arya LA, Myers DL, Jackson ND. Dietary caffeine intake and the risk for detrusor instability: a case-control study. Obstet Gynecol. 2002; 96:85. [PubMed: 10862848]

12. Tomlinson BU, Dougherty MC, Pendergast JF, et al. Dietary caffeine, fluid intake and urinary incontinence in older rural women. Int Urogynecol J. 1999; 10:22.

13. Bortolotti A, Bernardini B, Colli E, et al. Prevalence and risk factors for urinary incontinence in Italy. Eur Urol. 2000; 37:30. [PubMed: 10671782]

14. Bradley CS, Kennedy CM, Nygaard IE. Pelvic floor symptoms and lifestyle factors in older women. J Women's Health. 2005; 14:128.

15. Hannestad YS, Rortveit G, Dalveit AK, et al. Are smoking and other lifestyle factors associated with female urinary incontinence? The Norweigian EPINCONT Study. BJOG. 2003; 110:247. [PubMed: 12628262]

16. Tettamanti G, Altman D, Pedersen NL, et al. Effects of coffee and tea consumption on urinary incontinence in female twins. BJOG. 2011; 118:806. [PubMed: 21401855]

17. Dallosso HM, McGrother CW, Matthews RJ, et al. The association of diet and other lifestyle factors with overactive bladder and stress incontinence: a longitudinal study in women. BJU Int. 2003; 92:69. [PubMed: 12823386]

18. Jura YH, Townsend MK, Curhan G, et al. Caffeine intake, and the risk of stress, urgency and mixed urinary incontinence. J Urol. 2011; 185:1775. [PubMed: 21420114]

19. Bryant CM, Dowell CJ, Fairbrother G. Caffeine reduction education to improve urinary symptoms. Br J Nurs. 2002; 11:560. [PubMed: 11979209]

20. Swithinbank L, Hashim H, Abrams P. The effect of fluid intake on urinary symptoms in women. J Urol. 2005; 174:187. [PubMed: 15947624]

21. Sandvik H, Seim A, Vanvik A, et al. A severity index for epidemiological surveys of female urinary incontinence: comparison with 48-hour pad-weighing tests. Neurourol Urodyn. 2000; 19:137. [PubMed: 10679830]

22. U.S. Department of Agriculture, Agricultural Research Service, Beltsville Human Nutrition Research Center, Food Surveys Research Group (Beltsville, MD) and U.S. Department of Health and Human Services, Centers for Disease Control and Prevention, National Center for Health Statistics (Hyattsville, MD). What We Eat In America, NHANES 2005-2006. Available from: http://www.ars.usda.gov/Services/docs.htm?docid=18354Retrieved January 3, 2012 
23. Kroenke K, Spitzer RL, Williams JB. The PHQ-9: validity of a brief depression severity measure. J Gen Intern Med. 2001; 16:606. [PubMed: 11556941]

24. Barber MD, Walters MD, Bump RC. Short forms of two condition-specific quality-of-life questionnaires for women with pelvic floor disorders (PFDI-20 and PFIQ-7). Am J Obstet Gynecol. 2005; 193:103. [PubMed: 16021067]

25. National Center for Health Statistics, Centers for Disease Control and Prevention. [Website accessed on January 3,2012] Continuous NHANES Tutorial on Sampling Design. http:// www.cdc.gov/nchs/tutorials/Nhanes/SurveyDesign/SampleDesign/intro.htm

26. Kant AK, Graubard BI, Atchison EA. Intakes of water, moisture in foods and beverages, and total water in the adult US population - nutritional, meal pattern, and body weight correlates: National Health and Nutrition Examination Surveys 1999-2006. Am J Clin Nutr. 2009; 90:655. [PubMed: 19640962]

27. Kincade JE, Dougherty MC, Carlson JR, et al. Randomized clinical trial of efficacy of selfmonitoring techniques to treat urinary incontinence in women. Neurourol Urydn. 2007; 26:507. 


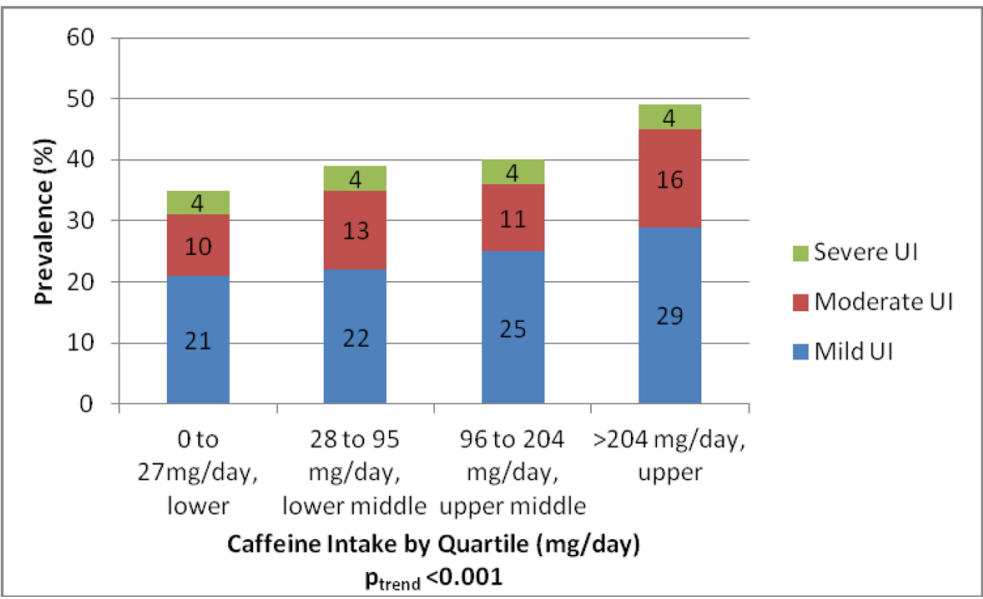

Figure 1.

Prevalence of Urinary Incontinence by Caffeine Quartiles US Women and Severity, data from the National Health and Nutrition Examination Survey 2005-06 and 2007-08 


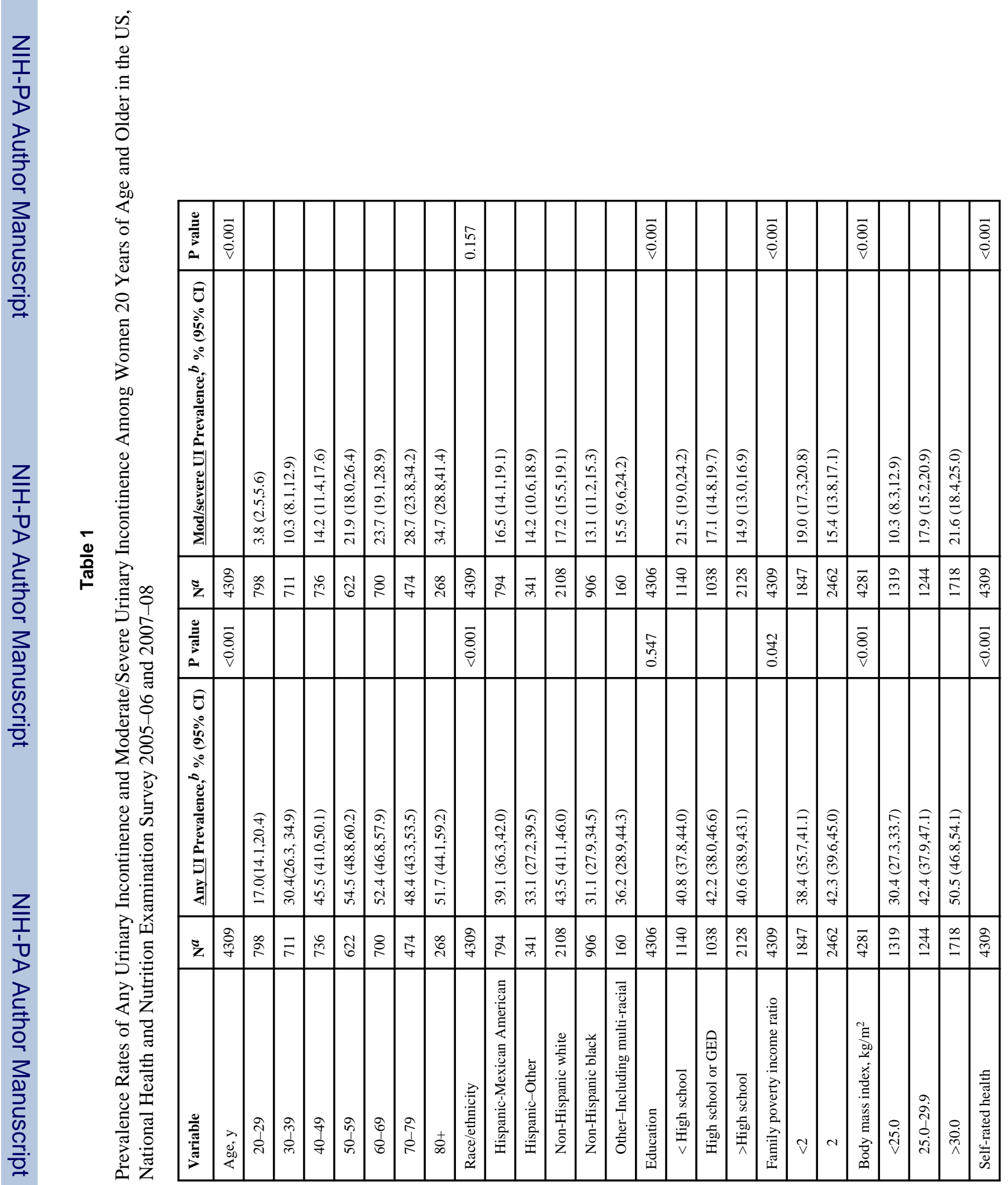




\begin{tabular}{|c|c|c|c|c|c|c|c|c|c|c|c|c|c|c|c|c|c|c|c|c|c|c|c|c|c|c|}
\hline 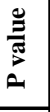 & & & $\begin{array}{l}\bar{\delta} \\
\dot{0} \\
\dot{\theta}\end{array}$ & & & $\begin{array}{l}\vec{\delta} \\
\dot{\theta}\end{array}$ & & & $\begin{array}{l}\overline{8} \\
\dot{v}\end{array}$ & & & & & $\begin{array}{l}\vec{\Delta} \\
\dot{\vec{v}}\end{array}$ & & & $\begin{array}{l}\bar{\delta} \\
\dot{\theta} \\
\dot{v}\end{array}$ & & & $\begin{array}{l}\bar{\delta} \\
\dot{\nabla} \\
\dot{v}\end{array}$ & & & & & & \\
\hline 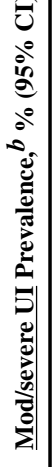 & 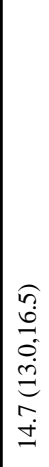 & $\begin{array}{l}0 \\
0 \\
d \\
c \\
0 \\
d \\
d \\
0 \\
0 \\
\dot{d}\end{array}$ & & $\begin{array}{l}a \\
0 \\
\hat{\sigma} \\
\dot{b} \\
\vec{b}\end{array}$ & 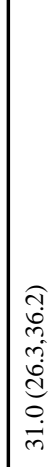 & & 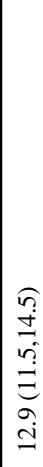 & $\begin{array}{l}0 \\
0 \\
0 \\
0 \\
d \\
d \\
0 \\
0 \\
0 \\
0\end{array}$ & & $\begin{array}{l}\stackrel{\partial}{\dot{j}} \\
\stackrel{m}{m} \\
\infty \\
\stackrel{0}{0} \\
\stackrel{0}{0}\end{array}$ & $\begin{array}{l}0 \\
0 \\
n \\
0 \\
0 \\
0 \\
0 \\
0 \\
\end{array}$ & 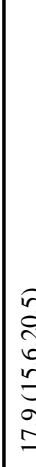 & 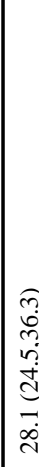 & & 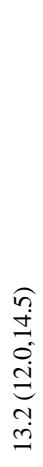 & 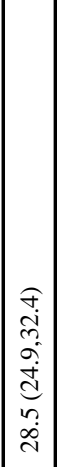 & & 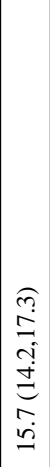 & 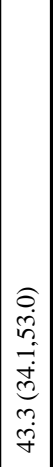 & & $\begin{array}{c}0 \\
0 \\
= \\
\vdots \\
\vdots \\
\vdots \\
n \\
a \\
0\end{array}$ & 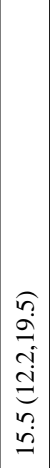 & 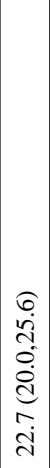 & 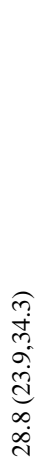 & 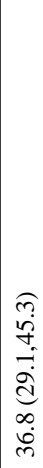 & 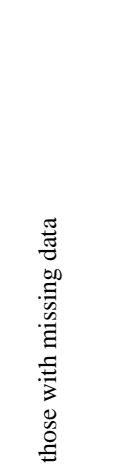 \\
\hline $\bar{z}$ & 总 & $\stackrel{\varrho}{\varrho}$ & $\begin{array}{l}\text { ने } \\
\text { fे }\end{array}$ & $\mid \begin{array}{l}3 \\
\infty \\
\infty\end{array}$ & Fे & ๙ิ & ల్లి & छे & $\underset{d}{\stackrel{+}{d}}$ & $\frac{\infty}{6}$ & 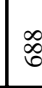 & 。 & $\overline{\mathrm{i}}$ & 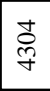 & 今े & $\stackrel{8}{\Xi}$ & $\begin{array}{l}\underset{f}{f} \\
\forall\end{array}$ & $\frac{8}{\gamma}$ & $\Xi$ & $\begin{array}{l}0 \\
\text { ปे } \\
y\end{array}$ & $\stackrel{\widetilde{Q}}{\Xi}$ & $\stackrel{\text { 品 }}{=}$ & 忘 & $\stackrel{\Xi}{\forall}$ & $\ddot{\sim}$ & \\
\hline 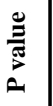 & & & $\begin{array}{l}\bar{\partial} \\
\dot{\nabla}\end{array}$ & & & $\begin{array}{l}\bar{\delta} \\
\dot{\nabla}\end{array}$ & & & $\begin{array}{l}\overline{8} \\
\dot{\nabla}\end{array}$ & & & & & $\begin{array}{l}\vec{\delta} \\
\dot{v} \\
\dot{v}\end{array}$ & & & $\begin{array}{l}\bar{\delta} \\
\dot{Q} \\
\dot{v}\end{array}$ & & & $\begin{array}{l}\bar{\delta} \\
\stackrel{\dot{\nabla}}{0}\end{array}$ & & & & & & 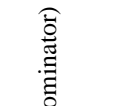 \\
\hline 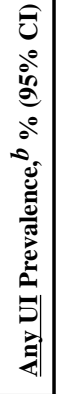 & 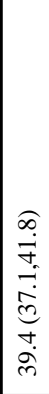 & $\mid \begin{array}{l}n \\
\tilde{n} \\
n \\
+ \\
\dot{j} \\
\dot{j} \\
o \\
o \\
\dot{\alpha}\end{array}$ & & 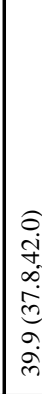 & 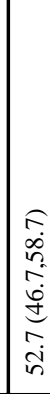 & & 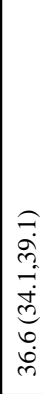 & 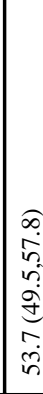 & & $\begin{array}{l}\text { ma } \\
\vdots \\
\dot{n} \\
m \\
\infty \\
\dot{m} \\
\dot{m}\end{array}$ & $\begin{array}{l}0 \\
0 \\
y \\
j \\
j \\
f \\
0 \\
n \\
2 \\
m\end{array}$ & $\mid \begin{array}{l}z \\
z \\
y \\
z \\
z \\
z \\
\vdots \\
y\end{array}$ & 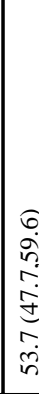 & & 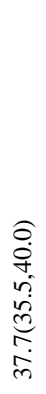 & 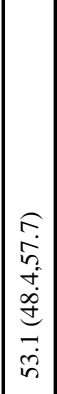 & & 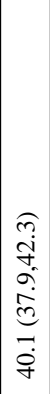 & $\begin{array}{l}0 \\
0 \\
0 \\
0 \\
-1 \\
0 \\
0 \\
0 \\
0 \\
0 \\
0\end{array}$ & & 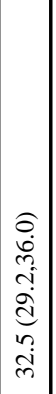 & 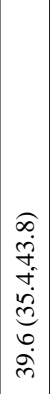 & 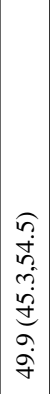 & 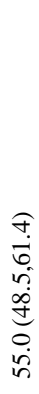 & 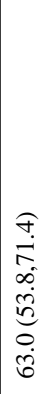 & 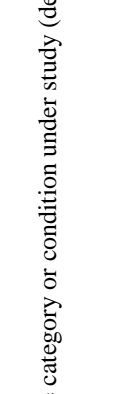 \\
\hline$\tilde{z}$ & 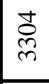 & $\stackrel{\overbrace{}}{\varrho}$ & 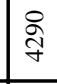 & $\begin{array}{l}\hat{\delta} \\
\infty \\
\sim\end{array}$ & $\widehat{F}$ & ๙ิ & జ్లో & छे & $\underset{d}{\stackrel{d}{d}}$ & $\frac{\infty}{\sigma}$ & $\stackrel{\infty}{\infty}$ & $\stackrel{5}{\circ}$ & $\bar{\AA}$ & 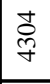 & ले & $\stackrel{\Xi}{\circ}$ & $\begin{array}{l}\vec{f} \\
\underset{f}{2}\end{array}$ & $\frac{8}{7}$ & $\bar{\Xi}$ & 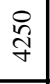 & $\stackrel{\Omega}{\varrho}$ & $\stackrel{\text { 寽 }}{=}$ & 忘 & $\frac{J}{f}$ & $\ddot{\sim}$ & \\
\hline 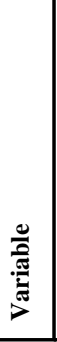 & 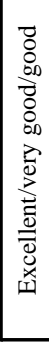 & 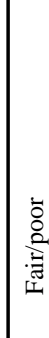 & 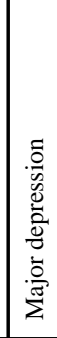 & 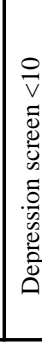 & 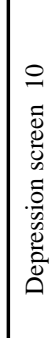 & 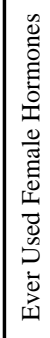 & $\stackrel{\circ}{z}$ & 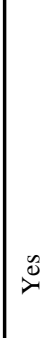 & 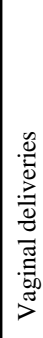 & 0 & $I$ & r & $x$ & 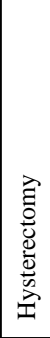 & ż & 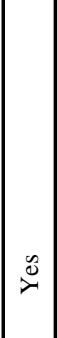 & 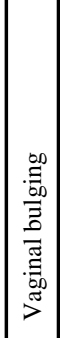 & z & 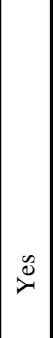 & 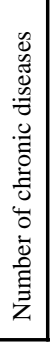 & . & - & . & & $\pi$ & 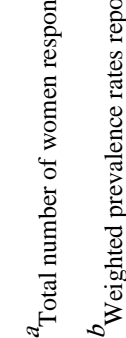 \\
\hline
\end{tabular}




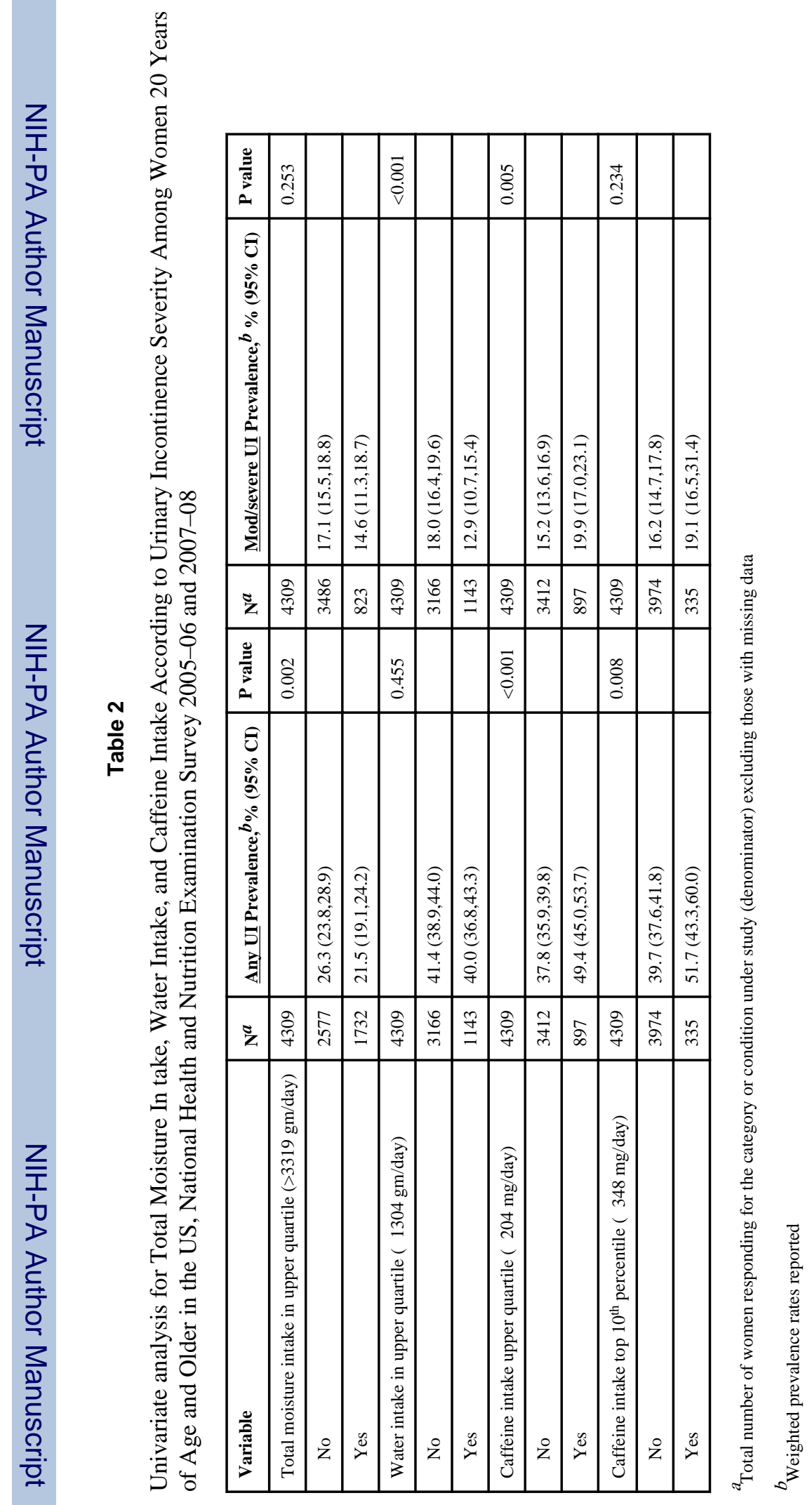


Table 3

Unadjusted and Adjusted Step-wise Multivariable Models for Caffeine Intake at the $75^{\text {th }}$ Percentile ( $\geq 204 \mathrm{mg}$ / day)

\begin{tabular}{|l|l|l|l|}
\hline & Cases & Any UI ${ }^{*}$ POR (95\% CI) & $\begin{array}{l}\text { Moderate/Severe UI } \\
\text { POR (95\% CI) }\end{array}$ \\
\hline Step 1: Unadjusted & 4309 & $1.60(1.34,1.91)$ & $1.38(1.11,1.73)$ \\
\hline Step 2: Sociodemographics (age, race, education, poverty status) & 4306 & $1.54(1.30,1.84)$ & $1.41(1.15,1.73)$ \\
\hline Step 3: Comorbidity and BMI & 4220 & $1.60(1.34,1.92)$ & $1.43(1.15,1.80)$ \\
\hline Step 4: Depression and Self- rated Health & 4205 & $1.59(1.33,1.90)$ & $1.43(1.14,1.79)$ \\
\hline Step 5: Alcohol use & 4204 & $1.60(1.36,1.91)$ & $1.48(1.18,1.86)$ \\
\hline Step 6: Water and total moisture intake from food and fluid & 4204 & $1.54(1.28,1.86)$ & $1.43(1.13,1.80)$ \\
\hline Step 8: Hysterectomy, hormone replacement therapy & 4186 & $1.53(1.27,1.84)$ & $1.40(1.10,1.75)$ \\
\hline Step 9: Vaginal deliveries & 2423 & $1.47(1.07,2.01)$ & $1.42(0.98,2.07)$ \\
\hline
\end{tabular}

* Separate logistic regression models created for "Any UI" and "moderate/severe UI" 